International Journal of Instruction e-ISSN: 1308-1470 • www.e-iji.net

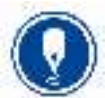

October $2020 \bullet$ Vol.13, No.4

p-ISSN: 1694-609X

$$
\text { pp. 361-374 }
$$

Received: 25/08/2019

Revision: $12 / 04 / 2020$

Accepted: 02/05/2020

OnlineFirst:19/07/2020

\title{
Number Talks Benefit Fifth Graders' Numeracy
}

\author{
Pamela L. May
}

Fifth Grade Teacher, 1316 Hans St., West Bend, WI 53090, 262-388-6720, Erin

Elementary School, USA, may@erinschool.org

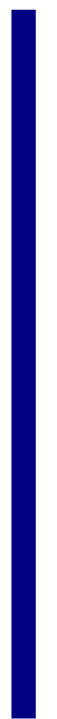

This researcher has been greatly distressed, as fifth graders year after year have disregarded mental math strategies for the standard algorithm. Mathematically proficient students should be flexible, efficient and accurate when solving mental calculations. This researcher set out to find out how fifth graders' mental math practice improved their numeracy. The questions addressed included how students improved in flexibility, accuracy and speed. This should inform the practice of teachers to help better our numeracy of our students. This article contends that Number Talks practiced two days a week, benefits numeracy in 22 fifth graders during a six-week cycle. In this Triangulation Mixed-Methods Design, data was collected that included pretest- posttest same test combined with an interview where the participants explained the strategies they used. The mean showed a greater improvement in the treatment group, however, paired-samples t-tests findings indicated flexibility and accuracy did not show a significant difference, but speed did incur a significant improvement. Additionally, students increased in their confidence when solving mental calculations. Moreover, an additional survey showed greater flexibility in the treatment group at the cycle's end. Number Talks, therefore may increase students' numeracy in the strand of efficiency. Researchers need to further study the degree practice through Number Talks improves numeracy in fifth graders.

Keywords: number talks, mathematics, strategies, addition, mental math, discourse

\section{INTRODUCTION}

A shocked look registered across her face as her mouth fell agape. Disbelieving eyes slowly shifted to acceptance as the student used her pointer finger to solve mentally a three-digit addition problem. She wrote invisible numbers aligned while her head started to bob as she laboriously calculated and rechecked. In the past, students in elementary school learned math by memorizing addition calculation steps. Standards for Mathematical Content, published in 2010 stated mathematically proficient students should be able to solve a problem using a strategy that fits it and be able to use various methods accurately and efficiently to calculate a problem (CCSSI, 2010). This study's focus was to increase number sense in fifth graders when using addition due to students

Citation: May, P. L. (2020). Number Talks Benefit Fifth Graders' Numeracy. International Journal of Instruction, 13(4), 361-374. https://doi.org/10.29333/iji.2020.13423a 
solely using the standard algorithm to solve addition problems. In the earlier years, students add and subtract within 100 using different mental math strategies based on place value and the relationship between subtraction and addition (CCSSI, 2010). As this author was working with fifth graders on mental math, almost every student had abandoned mental math strategies faithfully taught in the lower grades for the standard algorithm. Students wrote the numbers down using their finger while imagining the number in order to compute using the standard algorithm. They were not flexible in their thinking, and they did not use streamlined mental computation. Students described lining up the digits and carrying in their heads. It was the hope of this author that practicing mental math strategies through Number Talks, students would become more accurate and flexible thus improving their numeracy.

This research attempts to investigate the impacts on fifth graders' numeracy when students are sharing/teaching explicitly and practicing addition mental math strategies during a number discussion precipitated by a problem in context. The study's goal is to find a correlation between practicing mental math strategies by embedding story problems into Number Talk sessions and numeracy. In this way, experiential learning is combined with explicit teaching. Will practicing mental math strategies through Number Talks improve students' flexibility, accuracy, and speed? Note speed was a test for fluency.

\section{REVIEW OF LITERATURE}

In search of improving numeracy in fifth graders, the researcher drew upon the works of the early childhood scholar Ann Heirdsfield whose work in developing computational strategies can be used as a framework of how Number Talks can be used to improve numeracy in fifth graders Heirdsfield (2005). Much of the research focused on teaching preservice teachers numeracy skills, but it is critical elementary students utilize high levels of numeracy. This literature review first examines creating flexible thinkers. Next, the research presented explores explicit instruction and experiential learning. Finally, the review of literature will present ways to provide practice.

According to the Common Core State Standards (CCSSI, 2010), mathematical proficiency is a universal goal. Students must understand concepts and be flexible when choosing procedures. Under the category, Model with Mathematics, students should choose an efficient as well as appropriate model. This means students should approach any given problem with various ways to solve it, reason through the different strategies and solve the problem accurately and efficiently. If a student only uses the standard algorithm, this proficiency is not fostered (Erdem, 2016; Gürbüz \& Erdem, 2016). Additionally, according to the CCSSI (2010), mathematically proficient students can analyze problems and break the numbers into parts. Numeracy, having good number sense and the ability to compute mentally using number knowledge and their place values, is an essential tool in achieving these goals. When a student has developed sufficient number sense they are flexible in their thinking and can access various strategies while computing; they are flexible, accurate and efficient (Erdem, 2016; Gürbüz \& Erdem, 2016; Hinton, Stroizer, \& Flores, 2015). Studying children's numeracy progression is important. In kindergarten through grade two, students learn 
many number sense strategies such as "make a ten" and compensation. In grade three, students begin using the addition algorithm, the paper pencil method lining up the numbers horizontally one above the other with the columns lined up according to their place value. This strategy is inefficient because it does not aid calculation by drawing from different strategies (Erdem, 2016; Gürbüz \& Erdem, 2016). By the time students enter fifth grade, they have been using the addition standard algorithm for two years and mental math skills have diminished. When students stop practicing mental math, skills deteriorate (Olsen, 2015).

Numeracy aids mental calculation in adulthood (CCSSI, 2010). In order to be confident in mathematical skills as well as making correct calculations in day-to-day situations, students need to be able to calculate mentally. Early educators spend numerous classes working on numeracy, however, once the algorithm is introduced, many students use the standard algorithm as their go-to strategy (Al Mutawah, 2016). They need to learn at a deeper level and choose an efficient calculation strategy (Erdem, 2016; Gürbüz \& Erdem, 2016; Varol \& Farran, 2007).

As they move through their education, students develop mental math strategies. Young children show their mathematical flexibility when counting. They begin counting one by one. Later they learn counting in a shortened method, such as using whole groups of fives or tens. Older elementary students and adults manipulate the numbers in an efficient and accurate way (CCSSI, 2010; Humphreys \& Parker, 2015).

Some of the addition mental math strategies students use are: doubling, make a ten, decomposition, sequencing and compensation. Doubling is a strategy where the computation relies on the known double of numbers. Make a ten is a strategy in which students know many combinations to make a ten. This helps students reason out other addition problems such as eighteen plus twelve. Practicing the decomposition strategy (sometimes called split up strategies) teaches students to take a number apart and to add or subtract it to another number. For example, 7, 825 could be decomposed to its place values $7,000,800,20$, and 5 . Additional strategies for mental math computation are sequencing and compensating. In sequencing, one of the numbers in the calculation is retained as it appears and portions of the other number are added on. For example, 345 +75 could be calculated as $345+70+5$ or $345+25+50$. Compensating occurs when two numbers are added, but one number is made larger for calculation ease, and then the extra is taken off at the end to compensate. For example, $47+39$ can be added as 47 $+40=87$, then subtract the 1 for the answer 86 . Multiple studies have shown flexible thinking in students using these strategies. In one study, (Nursyahidah, Ilma, \& Somakim., 2013) first grade students used the make a ten and doubling strategies. In other studies, (Al Mutawah, 2016; Chen \& Bofferding, 2017; Rathgeb-Schnierer \& Green, 2017; Whitacre, 2014) thinking flexibility was measured by the ability to decompose, transform a problem, and add mentally without relying on the standard algorithm. 


\section{Explicit Instruction}

In a study done to improve preservice teachers' ability to understand and use mental math strategies, Al Mutawah, (2016) found the more preservice teachers practice, the more easily they were able to calculate using different mental math strategies throughout each day. In the end, $39 \%$ of the problems were solved using make a ten, $25 \%$ were using compensation, $38 \%$ were partitioning, $28 \%$ were solved using sequencing, and only $2 \%$ used the standard algorithm. This is significant because the baseline information showed the majority (72\%) used the standard algorithm. The researcher used a mixed method grounded theory study and a simple time-series. Through three cycles over a nine-week period, 47 preservice teachers learned through explicit instruction and increasingly used the mental math strategies. The preservice teachers were given quizzes at three stages, participated in interviews and were observed. The majority of the preservice teachers were using mental math strategies toward the end of the study. This information shows that practicing mental math strategies amongst adults improves numeracy. This study hopes to use this information and apply it to fifth graders.

Similarly, Whitacre (2014), used a one group pretest-post-test approach to study preservice teachers become more flexible in whole number thinking as a finding of explicit strategies instruction. The seven preservice teachers' flexibility levels consisted of inflexible, semi-flexible or flexible. The baseline data showed five of the seven participants were inflexible thinkers. Only one teacher remained dependent on the standard algorithm by the semester's end. The other six participants became more flexible in their thinking (Whitacre, 2014). Both studies show practicing mental math strategies even after learning the standard algorithm is necessary.

\section{Experiential Learning}

One grounded theory study, conducted by (Nursyahidah, et al., 2013), shows 33 first grade students learned by experience rather than by being explicitly taught. After the students had already learned the make a ten strategy with counters, they used real world problems to solve using numbers to twenty. Through play, they discovered how to move from informal counting (counting one by one) to formal levels using the strategies learned previously to make a ten. This study also included a traditional game called Dakocan consisting of a board with two sets of seven holes and 98 shells. The first graders came up with strategies such as doubles plus one, make a ten, and compensation. This supports experience and discovery rather than explicit strategy teaching. Additionally, students should be encouraged to discover their own computation strategies because this is a higher thinking skill Erdem (2016).

Additionally, the experiential learning method was the style used to understand the effect of Problem Based Learning (PBL), which means to use story problems as compared to direct instruction. In this quasi-experimental study, two fifth grade groups in Bandung learned using two different approaches. They took a test determining mathematical literacy. The literacy reliability was $(\mathrm{P}=0.785)$. Students taught using PBL with meaningful problems significantly outperformed with an average difference of 
.19 increase in mathematical literacy, those who learned using only direct instruction (Fery, Wahyudin, \&Tatang, 2017).

Some studies show combining explicit teaching with PBL during the Number Talks also supports flexible thinking. Number talks are discussions within a classroom where the students all come up with numerous ways to solve the problem. The teacher runs the discourse in a purposeful way. Boonen, Kolkman, \& Kroesbergen (2011) conducted a grounded theory study to see how kindergarteners grow in their mathematical skills because of how the teachers talk during a discussion. The 251 Dutch kindergarteners were all similar in their socioeconomic status as well as the visuospatial memory. The students performed number sense tasks. After the students engaged in math talks, teachers' math talks positively affected: measuring, counting skills, quantity comparison, number naming and cardinality. Additionally, the teachers' talk regarding numbers used for date, time and age had a positive effect. A negative relationship was found in: ordering, math talk diversity, number symbols and calculations. This study did not strongly suggest Number Talks were the best of both worlds, but there was some promise. In the current study this researcher attempted to collect evidence to support students' numeracy using Number Talks combined with the use of real-world problems of fifth graders.

Heirdsfield (2005) conducted another experiential learning experience. This case study included thirty-eight-year olds from Brisbane. In this ten-week study, lessons in strategies were the focus. However, the subjects were encouraged to solve mental addition and subtraction computations, but the students also discussed the strategies developed. The study findings were positive. The instructor noted her students were more positive and excited than they were in lessons not using this method. The students showed greater number sense by using and discussing numbers in a more flexible way. When reintroduced to the algorithm, students were able to use this strategy with understanding rather than going through memorized steps.

\section{Ways to Present Practice}

How teachers talk in discourse also is important. Chen \& Bofferding (2017) discovered some important talk moves were forgotten in their grounded theory study. Fourteen preservice teachers taught using discourse. They revoiced (the teacher restates what was just said) and pressed (the teacher asks the student to support their reasoning), but they forgot to ask the students to reason and orient (asking others to contribute to a student's strategy or thinking) themselves. Students needed to reevaluate how they obtained their answer, but the participants in the study did not encourage this. The number talk must be purposeful and enhance reasoning as well as teach strategies.

Information learned in a combined experimental and ex post facto design study revealed practice should be based on specific, instructional, evidence-based strategies (Fery, Wahyudin, \& Tatang, 2017; Hinton, et al., 2015). Two parallel sets of problems were tested on 78 students in second and fourth grade. One set assessed accuracy, and the other assessed strategy choice. 
In addition, one needs to take into consideration students' visual memories when designing an intervention. Children used decomposition strategies $55 \%$ of the time. They used counting-on (counting from a given spot rather than recounting all) $26 \%$ and other strategies $20 \%$. This strategy was found to be positively correlated to arithmetic accuracy $(\mathrm{P}=.23)$. It mediates the relationship between short-term visual spatial memory (VSM) and arithmetic accuracy (Foley, Vasilyeva, \& Laski, 2016). The researchers found that when students had stronger VSM they did better in computation than those with a lesser VSM. When students used decomposition, the students were more accurate.

The current state of the literature supports producing students with good number sense. This article contends Number Talks which are experiential in nature combined with PBL aide in increasing numeracy in fifth graders because students use more strategies to show flexible thinking, tackle the mental math problems with more confidence, are more accurate and significantly solve math problems faster.

\section{METHOD}

This study occurred in a rural, elementary, public school in southeastern Wisconsin. Twenty-two students were in both the experimental class and the control. The author analyzed the MAP (universal screener) data from the experimental group and the control group each consisting of eighteen students. The categorized data were according to three naturally separated ranges. The below benchmark group included three students who scored 210 or below; three students who were in the benchmarked range were from 211-215, and three students scoring in the above the norm range scored from 216 and above range.

The pre and posttests were one-step whole number mental addition story problems. The use of meaningful story problems was in accordance to the findings of Fery, et al., (2017). Students solved problems mentally and then described their thinking. Next, students solved four specific problems. The same story structure was used for each problem with different numbers substituted into each problem. The number pairs were carefully selected to encourage efficient strategy selection. Numbers for addition were selected if they needed regrouping. They were also put in a particular order so one question did not influence how students approached subsequent problems. Students then took part in an additional paper and pencil survey at the study's end to solve story problems using as many different strategies as they could.

All interviews were videotaped and audiotaped. In order to avoid interference with short-term memory, the numbers were in written form (Foley, et al., 2016). Participants solved the problems using mental math and explained specific strategies used. A thirdparty individual reviewed and rated this information.

The experimental group participated in Number Talks two days a week, twenty to thirty minutes each lasting six weeks while the control group only experienced their regular lessons designed for fifth graders. It did not experience Number Talks or any specific work on mental math improvement. The students gathered on a carpet in front of a Smart board where they solved numerous addition mental math problems. The number 
combinations were adapted from, Humphreys\& Parker (2015). When students had an answer, they indicated with a finger. If they had another strategy, students raised a second or third finger to indicate how many strategies they could explain. When all students had an answer, the participants were called on to explain the method used. The instructor used revoicing and pressing techniques, as well as asking students to reason and orient their thinking. After the session, a discussion ensued debating the strategy's efficiency. If the answer was inaccurate students explained where the problem went wrong. Each session was video/audiotaped, a journal was kept, and the Smart slides used were saved. The findings showed the students in the experimental group solved the mental math problems faster, more accurately and used more varied strategies than those in the control group. The findings indicate Number Talks may help increase number sense in fifth graders.

The purpose of this study was to discover if numeracy in the strands of accuracy, flexibility and speed would increase after practicing mental math strategies through Number Talks. The data collected was pretest- posttest same test combined with an interview where the participants explained the methods, they used to solve the problems (Mertler, 2017). This research used both quantitative and qualitative data in order to compare two groups' test findings and to determine the participants' thinking. Whitacre (2014), developed and used a flexibility scale, based off the work of Heirdsfield \& Cooper (2004). This scale categorized the degree of flexibility a student used to solve problems. Randomly chosen students from a fifth-grade pool scored below the norm, within the normed range and above the norm (three students from each category) on the MAP universal screener. The test group used the same random selection. The students were categorized as flexible, semi flexible or inflexible thinkers based off the pretest, posttest and the ending survey. A second rater categorized students using the videos. Both raters agreed on the flexibility levels assigned to each student.

Flexible mental calculators choose their strategy based on efficiency (Rathgeb-Schnierer $\&$ Green, 2017). Three or more strategies may be used. Semiflexible -some choices made based on the numbers in the problem (those who used two valid strategies) Inflexible- use one go to strategy such as the standard algorithm.

The author conducted two identical assessments on each group. The first test included a before and after the intervention assessment consisting of the same four addition questions in story context. The numbers were in context the interviews were recorded so the researcher and the interrater reviewer could assess the strategies the participants used. Four identical problems in context were administered to each student who then explained the mental calculation method. The calculation time and answer accuracy were recorded.

Both groups took an additional assessment consisting of the same questions from the interview. In this assessment, students solved the problems (using paper and pencil) in as many ways as they could. Only the correct answers were included in this data. The author used this additional measurement tool to help determine flexibility in student computation. The mean comparing the control to the experimental comparing accuracy, flexibility and speed as well as any possible $\mathrm{T}$ tests were calculated. 


\section{FINDINGS}

The first analysis of numeracy focused on the students' flexibility of thinking? A paired-samples t-test comparing the treatment group showed growth. The flexibility value was 1.735 showing an insignificant growth from pretest $(\mathrm{M}=0.17, \mathrm{SD}=.35)$ to posttest $(\mathrm{M}=.39, \mathrm{SD}=.44) ; \mathrm{t}=1.735, \mathrm{p}=.05$. Therefore, the hypothesis stating a significant difference between the pretest and posttest flexibility responses was rejected. Additionally, when comparing the control group findings, the paired-samples $\mathrm{t}$-test showed the value was zero. The pretest scores $(\mathrm{M}=0.06, \mathrm{SD}=.17)$ to posttest $(\mathrm{M}=.06, \mathrm{SD}=.17) ; \mathrm{t}=0, \mathrm{p}=.05$ also did not show a significant difference between them. A greater growth in the treatment group incurred when comparing the treatment group to the control group.

Table 1

Paired Samples Showing Treatment Groups' Flexibility, Accuracy and Speed

\begin{tabular}{lllllll}
\hline & & Mean & N & SD & T & $\mathrm{p}$ \\
\hline Pair 1 & Pretest Flexibility Interview & .17 & 9 & .35 & -1.74 & .05 \\
& Posttest Flexibility Interview & .39 & 9 & .44 & -1.74 & .05 \\
\hline Pair 2 & Pretest Accuracy & .36 & 9 & .42 & -1.49 & .05 \\
& Posttest Accuracy & .56 & 9 & .17 & -1.49 & .05 \\
\hline \multirow{2}{*}{ Pair 3 } & Pretest Speed & 72.69 & 9 & 29.77 & 4.11 & .05 \\
& Posttest Speed & 41.92 & 9 & 32.5 & 4.11 & .05 \\
\hline
\end{tabular}

The second numeracy analysis used a paired-samples t-test focused on students' accuracy. A paired-samples t-test showed the treatment group $\mathrm{t}=-1.49, \mathrm{p}=.05$. The pretest $(\mathrm{M}=0.36, \mathrm{SD}=.42)$ to posttest was $(\mathrm{M}=.56, \mathrm{SD}=.17)$. The hypothesis stating a significant difference between the pretest accuracy responses and the posttest accuracy responses was rejected. In addition, when comparing the control group findings, the paired samples t-test showed the value 1.049. The pretest $(\mathrm{M}=0.75, \mathrm{SD}=.48)$ to posttest $(\mathrm{M}=.59, \mathrm{SD}=.27) ; \mathrm{t}=1.049, \mathrm{p}=.05$. This also did not show a significant difference between them. The treatment group showed greater growth than the control group.

The final paired-sample t-test addressed mental math strategies through Number Talks improve students' speed? A paired samples t-test comparing the treatment group showed significant growth. The $\mathrm{t}$ value was $4.108, \mathrm{p}=.05$ showing a significant growth from pretest $(M=72.694, S D=29.77)$ to posttest $(M=41.92, S D=32.5)$. Therefore, the hypothesis stating a significant difference between the pretest speed responses and the posttest speed was not rejected. Additionally, when comparing the control group findings, the paired-samples t-test showed the value was .3939. The pretest $(M=55.17$, $\mathrm{SD}=18.25)$ to posttest $(\mathrm{M}=60.92, \mathrm{SD}=45.55) ; \mathrm{t}=-0.339, \mathrm{p}=.05$. This does show a significant difference between the treatment group as compared to the control group in the speed strand. Findings indicated in the table above which is in relevance with the result. 
Table 2

Mean Comparison of the End Survey Showing Ways to Solve Addition Problems (Flexibility)

\begin{tabular}{llll}
\hline & Experimental Mean & Control Mean & Change Experimental to control \\
\hline Problem 1 & 3.44 & 1.22 & 2.22 \\
Problem 2 & 3 & 1.22 & 1.78 \\
Problem 3 & 3.22 & 1.22 & 2 \\
Problem 4 & 2.88 & 1.22 & 1.66 \\
Mean & 3.14 & 1.22 & 1.92 \\
\hline
\end{tabular}

The final numeracy analysis was an additional paper and pencil test to determine students' flexibility of thinking. This analysis determined the mean of the amount of ways a student accurately calculated the same four addition problems in the pretest and posttest at the intervention cycle's end. The findings showed those in the treatment group had a mean of 3.14 solution strategies for the four problems. The control group had a mean of 1.22 solution strategies. The treatment group solved the problems an average 1.92 ways more than the control group. findings indicated in table 2 .

\section{DISCUSSION}

This research determined explicit instruction through peer-generated discussions that include aspects of experiential learning have improved the numeracy of fifth graders in two of the three categories tested. Number Talks create a setting where students can both learn explicitly from their peers as well as experience using the numbers in different strategies.

The findings of the current study were not conclusive in the area of flexibility. Students in both groups held tightly to the standard algorithm in the oral interview. However, when the paper pencil survey was analyzed, findings showed a much greater improvement in flexibility in the treatment group over the control group. The mean showed 3.14 strategies to solve the problems in the treatment group with only 1.22 strategies used to solve the problems in the control group. Findings show some improvement in the number of strategies used from the pretest to posttest in the treatment group, but it was not significant $(\mathrm{t}=1.74)$. Likewise, no improvement in the control group was noted $(\mathrm{t}=0)$. This supports the findings of many researchers, however only some of those studies included elementary aged students (Heirdsfield, 2005; Humphreys \& Parker 2015).

Al Mutawah (2016) provides additional support of explicit instruction. The increased practice of explicitly taught strategies showed significant improvement from the baseline information showing $72 \%$ of the problems solved using the standard algorithm initially, but after the treatment, only $2 \%$ of the problems were solved solely with the standard algorithm, which shows a dramatic increase in flexibility.

Similarly, Whitacre (2014) found an increase in flexible thinking amongst pre-service teachers who learned strategies explicitly. The Baseline data improved from two 
flexible thinkers to six flexible thinkers of the seven participants who were able to use place value and compensation strategies over a semester's time.

Another explicit instruction study was done with five children ages four through seven. Hinton, et al. (2015) used a collective case study; children were provided explicit instruction lasting two weeks. The students learned various counting techniques to help them recognize dots without counting them. They learned one-to-one counting (resultative counting) and to count on. The study supports using explicit instruction of mental math strategies for flexible thinking. Four of the five students began at zero sets of resultative counting and ended at five or six sets of resultative counting. One student grew from three to all six sets counted using resultative counting. Although this study showed explicit instruction had a positive impact on numeracy, it had very few participants and further studies are needed to investigate two like groups conducting an experimental design to see comparisons to other instructional types.

Some studies show teaching strategies directly or explicitly produces positive findings in flexible thinking, other studies support the opinion strategies should be experienced to promote flexible thinking. The students in the current study not only learned explicitly, but they also improved due to the discussion experience. Students were motivated to work on different strategies and explain them to their peers who listened intently and came up with their own strategies to solve problems. The students showed improvement in flexibility of thinking as well as accuracy.

Just as the current study has found, so too Heirdsfield (2005) found students showed a flexibility in number calculation. She conducted a ten-week case study with thirtyeight-year olds from Brisbane. The subjects were encouraged to solve mental addition and subtraction computations while the teacher engaged the students in strategy related discussions. The students engaged in strategic thinking when they explained their reasoning and analyzed what fellow students used to solve the computation. Just as in the current study, the students were more positive and excited than they were in lessons not using this method. In addition, the students showed a greater number sense using and discussing numbers in a more flexible way.

A strand in numeracy in the current research was directed at improvement in accuracy. The students were not significantly more accurate in the treatment group $(\mathrm{t}=1.50)$, but they were more accurate than the control group ( $\mathrm{t}=1.05)$. A study including 60 third year students in Brisbane showed flexible thinkers were more accurate because they knew their number facts, which helped the way they computed numbers. Some students applied their math facts skills to the mental computation of larger numbers (Heirdsfield \& Cooper, 2004). This suggests accuracy has more to do with accurate fact recall than practicing strategies. This enlightens the findings in the current study because fact knowledge could skew the results.

The final strand in numeracy was the speed or fluency. In the current study growth in speed was significant $(\mathrm{t}=4.11)$ as compared to the control group which only had a $\mathrm{t}$ score of 0.34 . This researcher was unable to find any current studies addressing the problem-solving speed. Perhaps this is because recent emphasis is on being a flexible 
thinker who chooses efficient strategies to best solve a problem. What is important is the reasoning and thinking behind the calculation. However, one can attempt to draw some conclusions from mental calculation speed. When questioned about how they reached their answer, the students most often used the standard algorithm. Consequently, one can say they were faster, but they cannot say it was due to increased fluency. However, one could surmise students were more comfortable calculating in their head and the practice they received during the intervention helped them to add more quickly. Knowledge of the students' math facts abilities would have been beneficial.

\section{CONCLUSIONS}

This researcher strives for a day when a fifth-grade student confidently looks the questioner in the eye, manipulates the numbers and proudly states the correct answer to a three-digit addition problem. Some studies support teaching the strategies explicitly to improve flexibility in thinking (Al Mutawah, 2016; Foley, et al., 2016; Hinton, et al., 2015; Whitacre, 2014), while others support strategies in context (Fery, Wahyudin, \& Tatang, 2017; Nursyahidah, et al., 2013). Problems should be presented in context using real word type problems (PBL). One way to do this is through Number Talks (Boonen, et al., 2011) that generate discussions on strategies and promote reasoning as long as the teacher fosters the reasoning during the discussion (Chen \& Bofferding, 2017; Heirdsfield, 2005).

This article contends Number Talks aide in increasing numeracy in fifth graders because students use flexible thinking strategies, tackle the mental math problems with more confidence, are more accurate and significantly solve math problems faster.

It is unclear if practicing mental math strategies through Number Talks improve students' flexibility of thinking. Although the paired samples findings suggest students do not significantly improve in flexibility, when tested using mental math a positive relationship was noted. Furthermore, the findings may suggest the importance of taking into account the method in which the flexibility of students is tested. The treatment group students did outperform the control group when they solved the problems using as many strategies as they could when using pencil and paper. It is also not evident if practicing mental math strategies through Number Talks improves students' accuracy. The accuracy showed some growth but not statistically significant. In addition, the control group showed a negative relationship not statistically strong enough to show regression. Practicing mental math strategies through Number Talks may improve students' speed, which showed a significant statistical relationship.

Therefore, further research is needed to see if practicing mental math strategies through Number Talks will improve numeracy in fifth graders. Students in fifth grade had solidified their preferences in mental calculation strategies. They did not appear to spend time evaluating various possible strategies before trying to solve the problem. Perhaps the Number Talks should include an emphasis on evaluating strategies stage. Further studies on third and fourth graders would be very helpful in determining when this preference solidifies in order to assist student flexible thinking. 
The pretest and posttest experimental group interviews show other positive outcomes not formally tested. Students were much more relaxed during the posttest interviews. One student during the pretest interview said, "I don't know," after he had given his answer. This suggested a lack of confidence. The same student answered all posttest questions much more confidently than his pretest interview. The treatment students did not rely on writing the numbers in the air with their fingers as they often did on the pretest, which would suggest students had increased their ability to hold numbers in their brain as well as greater comfort and confidence levels. Whereas the students in the control group generally pointed and used their fingers in both the pre-interview and the post interview. The fact speed showed a statistical improvement in the treatment group could also help show this improved mental capacity. In addition, those in the treatment group did not look shocked at what the mental math problems involved.

This researcher saw the impact on student learning as well as determined what aspects make up improving numeracy. In the future, Number Talks in this researcher's classroom will be helpful in teaching students thinking flexibly in all four operations as well as a tool for slowing down and analyzing mathematical relationships students seem to be having difficulty grasping.

\section{LIMITATIONS AND DIRECTION FOR FUTURE RESEARCH}

One limitation was the author was also the teacher. The current study also had a small sample size and was conducted over a short time frame. Analyzing settings across multiple grade levels would have provided a more accurate picture.

One area to improve is increasing the weeks from six to eight. More time could then be spent talking about efficiency of the calculation strategies. In this manner, students would practice those important planning steps. Another improvement to the study may be to implement other practice methods in addition to Number Talks such as number circles and games.

Other research suggested from the findings of this study may be to study beginning fourth graders rather than fifth graders. During fourth grade, students apply all strategies learned in third grade. If students at this age level continue to practice mental math methods, they may enter fifth grade more equipped to make decisions about the best way to solve a problem when adding. Another study one might conduct is studying how the increase in the number sense boosts math confidence and students' willingness to persevere and take on new math challenges. More studies are also needed to study the fluency and accuracy in flexible thinking students.

Another area to be investigated is the way the algorithm is presented in the classroom and how it is reinforced at home. Many parents are relieved when their child learns the algorithm. This could affect the child making them somehow think the algorithm is the best way to solve problems. 


\section{REFERENCES}

Al Mutawah, M. A. (2016). The effect of practicing mental calculation strategies on teacher candidates' numeracy proficiency. International Journal of Education and Literacy Studies, 4(2), 1-12. doi: 10.7575/aiac.ijels.v.4n.2p.1.

Boonen, A. J., Kolkman, M. E., \& Kroesbergen, E. H. (2011). The relation between teachers math talk and the acquisition of number sense within kindergarten classrooms. Journal of School Psychology, 49(3), 281-299. doi: 10.1016/j.jsp.2011.03.002.

Chen, L., \& Bofferding, L. (2017). Interpreting and representing students' thinking in the moment: preservice teachers' initial number string lessons. North American Chapter of the International Group for the Psychology of Mathematics Education, 39, 813-820.

Common Core State Standards Initiative (CCSSI). (2010). Common core state standards for mathematics. Washing n, DC: National Governors Association Center for Best Practices and the Council of Chief State School Officers.

Erdem, E. (2016). Mental computation: Evidence from fifth graders. International Journal of Science and Mathematics Education, 15(6), 1157-1174. doi: 10.1007/s10763-016-9722-1.

Fery, M. F., Wahyudin, \& Tatang, H. (2017). Improving primary students' mathematical literacy through problem based learning and direct instruction. Educational Research and Reviews, 12(4), 212-219. doi: 10.5897/err2016.3072.

Foley, A. E., Vasilyeva, M., \& Laski, E. V. (2016). Children's use of decomposition strategies mediates the visuospatial memory and arithmetic accuracy relation. British Journal of Developmental Psychology, 35(2), 303-309. doi: 10.1111/bjdp.12166.

Gürbüz, R., \& Erdem, E. (2016). Relationship between mental computation and mathematical reasoning. Cogent Education,3(1), 1212683. doi: 10.1080/2331186x.2016.1212683.

Heirdsfield, A., \& Cooper, T. J. (2004). Factors affecting the process of mental addition and subtraction: Case studies of flexible and inflexible computers. Journal of Mathematical Behavior, 23(4), 443-463.

Heirdsfield, A. (2005). One teacher's role in promoting understanding in mental computation. International Group for the Psychology of Mathematics Education (Vol. 3, p. 29). Retrieved from http://www.remote.uwosh.edu/login?url=http://search.ebscohost.com/login.aspx?direct= true \&AuthType=ip,uid\&db=eric\&AN=ED496898\&site=ehost-live \&scope=site.

Hinton, V., Stroizer, S., \& Flores, M. (2015). A case study in using explicit instruction to teach young children counting skills. Investigations in Mathematics Learning, 8(2), 37-54. doi: 10.1080/24727466.2015.11790350. 
Humphreys, C., \& Parker, R. E. (2015). Making number talks matter: Developing mathematical practices and deepening understanding, grades 4-10. Portland, ME: Stenhouse.

Mertler, C. A. (2017). Action research: Improving schools and empowering educators. Los Angeles: SAGE

Nursyahidah, F., Ilma, R., \& Somakim, S. (2013). Supporting first grade students' understanding of addition up to 20 using traditional game. Journal on Mathematics Education, 4(2), 212-223. doi: 10.22342/jme.4.2.557.212-223.

Olsen, J. R. (2015). Five keys for teaching mental math. The Mathematics Teacher, 108(7), 543-547. doi: 10.5951/mathteacher.108.7.0543.

Rathgeb-Schnierer, E., \& Green, M. (2017). Mental arithmetic and cognitive flexibility in elementary students. INTED 2017 Proceedings (353-362). doi: 10.21125/inted.2017.0252.

Varol, F., \& Farran, D. (2007). Elementary school students' mental computation proficiencies. Early Childhood Education Journal, 35(1), 89-94. doi: 10.1007/s10643007-0173-8.

Whitacre, I. (2014). Strategy ranges: Describing change in prospective elementary teachers' approaches to mental computation of sums and differences. Journal of Mathematics Teacher Education, 18(4), 353-373. doi: 10.1007/s10857-014-9281-8.

Wisconsin Department of Public Instruction. (2018). The 2018 WISEdash annual report Wisconsin State Report Cards Erin Elementary. Retrieved from https://apps2.dpi.wi.gov/reportcards/home. 